\title{
Comparison of Control Techniques for Three-Phase Distributed Generation Based on VOC and DPC
}

\author{
Graziella Giglia\#, Marcello Pucci\# , Member IEEE, \\ Calogero Serporta\#, Gianpaolo Vitale\#, Member IEEE, \\ \# I.S.S.I.A.-C.N.R. (Institute on Intelligent Systems for the Automation), Palermo - Italy, \\ Via Dante, 1290141 PALERMO, ITALY, Tel. +39 0916113513 Fax +39 0916113028 \\ giglia@pa.issia.cnr.it, marcello.pucci@ieee.org, serporta@pa.issia.cnr.it, gianpaolo.vitale@ieee.org
}

\begin{abstract}
This paper presents a comparison among control strategies of active rectifiers used for grid connected distributed generation systems from renewable sources.

The considered techniques are: Voltage Oriented Control (VOC), Direct Power Control (DPC), two DPC based techniques to minimize the Common Mode (CM) emissions called DPC-EMC1 and DPC-EMC2 set up by the authors and their versions based on virtual flux.

All the described techniques have been implemented using Matlab-Simulink ${ }^{\circledR}$ environment and PLECS ${ }^{\circledR}$.

In the results the current injected into the grid, the THD of the injected current vs. generated power and vs. DC link voltage and the $\mathrm{CM}$ voltage are shown.
\end{abstract}

\section{Keywords}

Distributed Generation, Voltage oriented Control, Direct Power Control

\section{Introduction}

Recently, there has been a significant development of active rectifiers control techniques [1]. This trend is mainly due to the harmonic pollution of power systems caused by the commonly used line-side diode rectifiers. As a matter of fact, active rectifiers are the alternative solution to the use of either passive or active filters. The most common control strategies of active rectifiers are based on current control of VSIs [2]. Among these, one of the most adopted is the so called VOC (Voltage Oriented Control), where the current control is performed in the voltage space-vector oriented reference frame [3][5]. Another approach is based on the idea of controlling directly the active and reactive powers by choosing the proper switching patterns on the basis of the instantaneous position of the grid voltage space-vector [6]. This technique has been called DPC (Direct Power Control). On the basis of a parallelism between the electrical grid and an electrical machine, both VOC and DPC have been further improved in their virtual flux based versions, called respectively VF-OC (Virtual Flux) and VF-DPC [7][8]. A comprehensive theoretical and experimental comparison of these techniques have been done in [9], where however the focus is the behaviour in case of a controlled load, in particular an adjustable speed drive. However, controlled rectifiers present the additional advantage of their bi-directional power flow. Therefore, control techniques devised for active rectifiers can be properly used also for grid connected VSI for distributed generation, from renewable sources. In [10] a first comparative analysis of classic VOC and DPC techniques in generating mode has been done. With this regard a new DPC control technique, called DPC-EMC (Electromagnetically Compatible), has been devised for 3-phase distributed generation systems from renewable sources (photovoltaic, eolic, Fuel-cells etc.) [11][12]. This technique, developed in two versions called respectively DPC EMC 1 and DPC EMC 2, permits the reduction of the common-mode emissions generated by the VSI towards the grid, by using either even or odd voltage vectors in each of the six sectors in which the grid voltage lies, without using any null vector. These approaches permit the common-mode emissions to be reduced in comparison with the classic DPC algorithm, at the expense of a slight increase of the harmonic content of the injected current waveform.

This paper presents a comparison of VOC and DPC techniques, but focuses the attention to their behaviours when used in generating mode, e.g. for grid connected distributed generation systems from renewable sources. Differently from [10], where only a comparison between the classic VOC and DPC have been done, in this work the comparative analysis has been extended also to the virtual flux versions of VOC and DPC, called VF-OC and VF-DPC, and to the DPC EMC 1 and DPC EMC 2. With this regard the virtual flux versions of these last two techniques have been set up and implemented. Finally, the ratio between the DC link voltage and the grid voltage amplitude has been taken into account with regard to its influence on the THD of the injected currents.

Results have been compared from the point of view of the harmonic content of the currents injected into the grid, the THD of the injected current vs. generated power and vs. DC link voltage. Finally, results have been compared also with the requirements of the European [13] and American [14] standards.

\section{VOC and DPC Techniques}

Both VOC and DPC have been directly derived from their counterparts, formerly devised for the control of 
electrical drives, called respectively FOC (Field Oriented Control) and DTC (Direct Torque Control). As in the drive control counterpart, the VOC is based on the idea to find a rotating reference frame in which the current control corresponds to the active and reactive power control. On this basis firstly the VOC has been developed, where the direct axis lies in the direction of the grid voltage space vector, secondly the virtual flux (VF) VOC has been developed, where the direct axis lies in the direction of a virtual flux, obtained on the basis of the time integration of the grid voltage components. Obviously, since the virtual flux lies in quadrature with respect to the grid voltage, the direct and quadrature components of the injected currents are interchanged with respect to the VOC. At the same time, as in the drive control counterpart, DPC is based on the idea to find instantaneously a switching pattern of the inverter permitting to increase or decrease directly, without current control, and in a decoupled way the active and reactive power exchange between the DC stage and the grid. Even in this case the virtual flux (VF) DPC has been developed as a further improvement, where active and reactive powers are estimated on the basis of the virtual flux components instead of the voltage ones. In [8] and [9] extensive comparisons between VOC, DPC, VF-VOC and VF-DPC have been done, even if the attention is focused on the controlled load behaviour and it has been shown that the virtual flux version of each technique permits to obtain improvements in terms of active and reactive power ripples and in terms of harmonic content of the injected currents. Since the behaviour of the control systems as a controlled load or a generation system is not perfectly symmetric, particularly in the DPC case, in this paper only the behaviour as generator is addressed. Moreover, the virtual flux versions of the proposed techniques have not been here analyzed and will be subject of a future analysis. In the modelization of both control systems explained below it has been assumed that the power is positive when it is absorbed by the DC source from the grid: therefore powers generated by renewable sources are assumed negative.

\section{A. Voltage Oriented Control}

Voltage oriented control is based on the idea of decoupling instantaneously the direct and quadrature components of the injected current, working in the grid voltage space-vector reference frame. In this synchronous reference frame, the voltage space-vector equations of the system are:

$\mathbf{u}_{g}^{u}=\mathbf{u}_{s}^{u}+L \frac{d \mathbf{i}_{s}^{u}}{d t}+R \mathbf{i}_{s}^{u}+j \omega L \mathbf{i}_{s}^{u}$

For the symbols, see the list at the end.

The decomposition of such equations on the direct (d) and quadrature $(\mathrm{q})$ axis gives: $\left\{\begin{array}{l}u_{g d}=u_{s d}+R i_{s d}+L d i_{s d} / d t-\omega L i_{s q} \\ u_{g q}=u_{s q}+R i_{s q}+L d i_{s q} / d t+\omega L i_{s d}\end{array}\right.$

Eq. (2) shows that the direct (quadrature) component of the injected currents depends on the direct (quadrature) component of the inverter voltages. However, as it is in the electrical drive counterpart, there are some coupling terms on both axis equations, which should be compensated with feed-forward control terms. Same consideration is true for the direct component of the grid voltage which should be compensated with a suitable feed-forward term.

Since the target here is to control directly the active and reactive power, the control scheme has been slightly modified so to compute the current references from the power ones. On this basis, the expressions of $\mathrm{P}$ and $\mathrm{Q}$ in the synchronous reference frame have been considered:

$P=\frac{3}{2} u_{g d} i_{s d}, Q=-\frac{3}{2} u_{g d} i_{s q}$

From $3 \mathrm{a}, \mathrm{b}$ the $\mathrm{d}$, $\mathrm{q}$ reference current components can be obtained on the basis of the reference active and reactive power. With regard to the current control, it can be derived directly from eq. (3a,b), considering that a feedforward compensation of some terms should be considered. The direct and quadrature components of the inverter voltage $\mathrm{s}$ can be then computed as:

$$
\begin{gathered}
u_{s d}=\omega L i_{s q}+u_{g d}+\Delta u_{s d} \\
u_{s q}=-\omega L i_{s d}+\Delta u_{s q}
\end{gathered}
$$

Where PI controllers are used for controlling the current error to zero in this way, forcing the current error on both axis to zero:

$$
\begin{aligned}
& \Delta u_{d}=k_{p}\left(i_{\text {dref }}-i_{d}\right)+k_{1} \int\left(i_{\text {dref }}-i_{d}\right) d t \\
& \Delta u_{q}=k_{p}\left(i_{\text {qref }}-i_{q}\right)+k_{1} \int\left(i_{\text {qref }}-i_{q}\right) d t
\end{aligned}
$$

The entire control scheme is shown in Fig. 1, which exhibits the well known decoupling terms. It is slightly different from [6]-[9] where the direct component of the reference current is computed as the output of a DC link voltage controller. Current control is performed in the grid voltage reference frame by means of PI (Proportional Integral) controllers. An Asynchronous space vector modulation (SVM) technique with PWM frequency of $5 \mathrm{kHz}$ has been adopted. The sampling frequency of the entire control system has been set to 10 $\mathrm{kHz}$. 


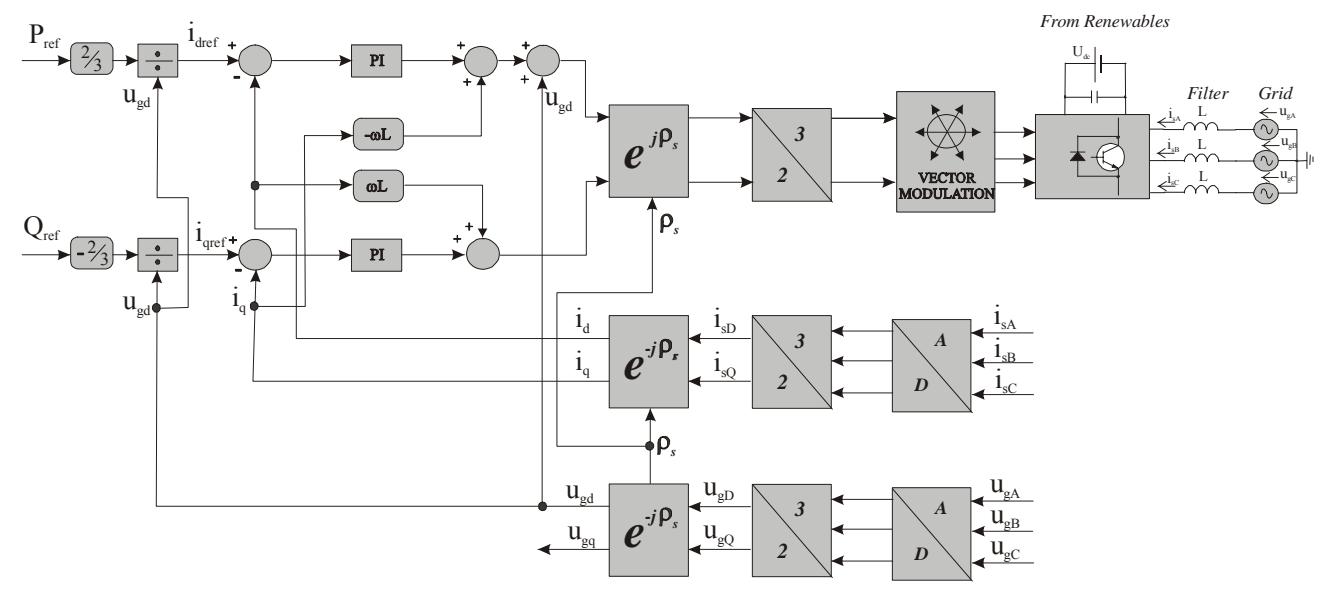

Fig. 1: Block diagram of the VOC scheme

\section{B. Direct Power Control}

Direct Power Control is based on the idea to control directly and in a decoupled way the active and reactive power exchanged by the inverter with the electrical grid, avoiding any current control. The optimal switching pattern is to be selected on the basis of the active and reactive power demand and depends on the instantaneous position of the grid voltage space-vector. It can be shown that if the grid voltage vector $\mathbf{u}_{\mathrm{g}}$ lies instantaneously in the sector $k$, the effect on the active and reactive power, $\mathrm{P}$ and $\mathrm{Q}$, exchanged with the grid caused by the application of any VSI voltage vector can be synthesized in Table I, which takes also into consideration each sub-sector inside a sector (A is the first and B the second sub-sector in the rotating sense of the grid voltage vector [8]). In the table, a single arrow means a small variation while a double arrow a big variation.

Table. I: Effect of the VSI voltage vectors on P and Q

\begin{tabular}{|c|c|c|c|c|c|c|c|}
\hline & $\mathbf{u}_{0}$ & $\mathbf{u}_{\mathbf{k}}$ & $\mathbf{u}_{k+1}$ & $\mathbf{u}_{\mathbf{k}+2}$ & $\mathbf{u}_{\mathrm{k}+3}$ & $\mathbf{u}_{\mathrm{k}-1}$ & $\mathbf{u}_{\mathrm{k}-2}$ \\
\hline $\bar{P}$ & $\Uparrow \Uparrow$ & 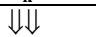 & $\Uparrow \Uparrow \Uparrow$ & $\pi \Uparrow$ & $\pi \Uparrow$ & $\Uparrow$ & $\pi \Uparrow$ \\
\hline $\mathrm{Q}$ & $\Uparrow_{\mathrm{A}} \mathrm{\Downarrow} \Downarrow_{\mathrm{B}}$ & $\Uparrow_{\mathrm{A}} \Downarrow_{\mathrm{B}}$ & 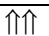 & $\Uparrow$ & $\Downarrow_{\mathrm{A}} \Uparrow \mathrm{B}$ & \ฟ & $\Downarrow$ \\
\hline
\end{tabular}

On the basis of Tab. I, the optimal switching table proposed by [6] can be directly deduced. This switching table, synthesized in Tab. II, has been used here for the experimental application of the methodology.

Table. II: Optimal switching tab
\begin{tabular}{|c|c|c|c|}
\hline \multirow{2}{*}{$\mathrm{P} \Uparrow$} & $\mathrm{Q} \Uparrow$ & $\mathbf{u}_{0}$ & $\mathbf{u}_{0}$ \\
\cline { 2 - 5 } & $\mathrm{Q} \Downarrow$ & $\mathbf{u}_{\mathbf{k}-1}$ & $\mathbf{u}_{0}$ \\
\hline $\mathrm{P} \Downarrow$ & $\mathrm{Q} \Uparrow$ & $\mathbf{u}_{\mathbf{k}}$ & $\mathbf{u}_{\mathbf{k}+1}$ \\
\cline { 2 - 4 } & $\mathrm{Q} \Downarrow$ & $\mathbf{u}_{\mathbf{k}-1}$ & $\mathbf{u}_{\mathbf{k}}$ \\
\hline
\end{tabular}

The active and reactive power for control feedback have been estimated instantaneously on the basis of the following equations:

$$
\begin{aligned}
& P=u_{s A} i_{s A}+u_{s B} i_{s B}+u_{s C} i_{s C}, \\
& Q=\frac{1}{\sqrt{3}}\left(\left(u_{s B}-u_{s C}\right) i_{s A}+\left(u_{s C}-u_{s A}\right) i_{s B}+\left(u_{s A}-u_{s B}\right) i_{s C}\right)
\end{aligned}
$$

The three-phase quantities of the inverter voltages and currents have been used for the computation of the active and reactive powers, and thus no coordinate variation is need differently from the VOC. The entire control scheme is shown in Fig. 2. Active and reactive power control is done by two-level hysteresis controllers. A sector and subsector finding algorithm permits to compute where the grid voltage vector instantaneously lies, with the approximation of $\pi / 6 \mathrm{rad}$. The sampling frequency of the DPC control system has been set equal to $15 \mathrm{kHz}$.

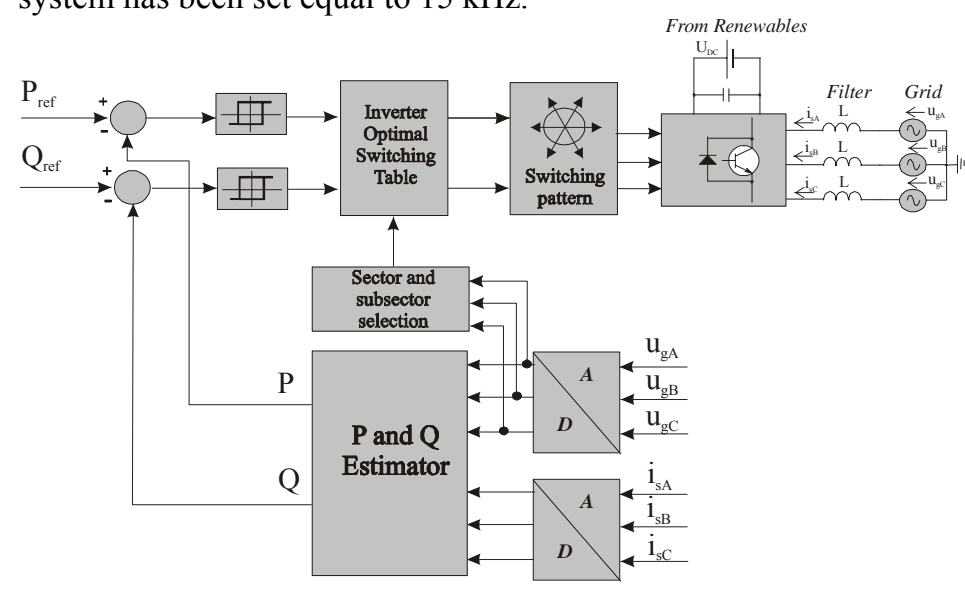

Fig.2: Block diagram of the DPC control schemes

\section{DPC-EMC 1}

Tab. III, which presents the common-mode voltage for each inverter state, shows that, if only even or only odd active voltage vectors are used ( $\mathbf{u}_{\mathbf{k}}$, with $k$ respectively even or odd), no common-mode voltage variation is generated. If a transition from an even voltage vector to an odd one (or vice versa) occurs, a common-mode variation of amplitude $\mathrm{U}_{\mathrm{DC}} / 3$ is generated. If a transition from an odd (even) voltage vector to the zero (seventh) voltage vector occurs, a common-mode variation of amplitude $\mathrm{U}_{\mathrm{DC}} / 3$ is generated. Finally, if a transition from an odd (even) voltage vector to 
the seventh (zero) voltage vector occurs, a common-mode variation of amplitude $2 \mathrm{U}_{\mathrm{DC}} / 3$ is generated. Therefore, from the point of view of common-mode emissions, the worst case is a transition from an odd (even) voltage vector to the seventh (zero) voltage vector.

For this reason, whatever inverter control technique is devised, to minimize the generated common-mode emissions of the drive, the exploitation of both null voltage vectors (zero and seventh) should be avoided. If a DPC technique is used, this consideration is helpful also from the control point of view. As a matter of fact, the original DPC [6] has been devised so that the zero voltage vector is adopted when a $\mathrm{P}$ increase is needed when both a $\mathrm{Q}$ increase and decrease are needed (see Tab. IV).

Actually, when the grid voltage vector lies in the $\mathrm{k}^{\text {th }}$ sector, the application of the $\mathrm{k}^{\text {th }}$ voltage vector produces a high decrease of the absorbed active power and a low increase (sub-sector A) or decrease (sub-sector B) of the reactive power.

On the contrary, the application of the $\mathrm{uk}_{+2}$ voltage vector produces a slight increase both of the active and reactive power while the $\mathrm{uk}_{-2}$ voltage vector produces a slight increase of the active power and a decrease of the reactive power.

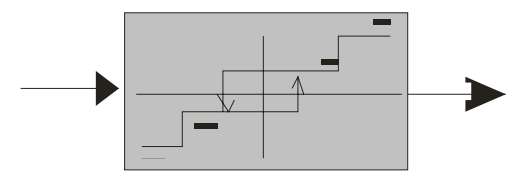

Fig.3: 4-level hysteresis controller

Table. III: Inverter states and common voltages

\begin{tabular}{lrrrr}
\hline State & $\mathrm{u}_{\mathrm{SA} 0}$ & \multicolumn{1}{c}{$\mathrm{U}_{\mathrm{SB} 0}$} & $\mathrm{u}_{\mathrm{SC} 0}$ & $\mathrm{u}_{\mathrm{com}}$ \\
\hline $\mathbf{u}_{\mathbf{0}}(0,0,0)$ & $-\mathrm{U}_{\mathrm{DC}} / 2$ & $-\mathrm{U}_{\mathrm{DC}} / 2$ & $-\mathrm{U}_{\mathrm{DC}} / 2$ & $-\mathrm{U}_{\mathrm{DC}} / 2$ \\
$\mathbf{u}_{\mathbf{1}}(1,0,0)$ & $\mathrm{U}_{\mathrm{DC}} / 2$ & $-\mathrm{U}_{\mathrm{DC}} / 2$ & $-\mathrm{U}_{\mathrm{DC}} / 2$ & $-\mathrm{U}_{\mathrm{DC}} / 6$ \\
$\mathbf{u}_{2}(1,1,0)$ & $\mathrm{U}_{\mathrm{DC}} / 2$ & $\mathrm{U}_{\mathrm{DC}} / 2$ & $-\mathrm{U}_{\mathrm{DC}} / 2$ & $\mathrm{U}_{\mathrm{DC}} / 6$ \\
$\mathbf{u}_{3}(0,1,0)$ & $-\mathrm{U}_{\mathrm{DC}} / 2$ & $\mathrm{U}_{\mathrm{DC}} / 2$ & $-\mathrm{U}_{\mathrm{DC}} / 2$ & $-\mathrm{U}_{\mathrm{DC}} / 6$ \\
$\mathbf{u}_{4}(0,1,1)$ & $-\mathrm{U}_{\mathrm{DC}} / 2$ & $\mathrm{U}_{\mathrm{DC}} / 2$ & $\mathrm{U}_{\mathrm{DC}} / 2$ & $\mathrm{U}_{\mathrm{DC}} / 6$ \\
$\mathbf{u}_{5}(0,0,1)$ & $-\mathrm{U}_{\mathrm{DC}} / 2$ & $-\mathrm{U}_{\mathrm{DC}} / 2$ & $\mathrm{U}_{\mathrm{DC}} / 2$ & $-\mathrm{U}_{\mathrm{DC}} / 6$ \\
$\mathbf{u}_{\mathbf{6}}(1,0,1)$ & $\mathrm{U}_{\mathrm{DC}} / 2$ & $-\mathrm{U}_{\mathrm{DC}} / 2$ & $\mathrm{U}_{\mathrm{DC}} / 2$ & $\mathrm{U}_{\mathrm{DC}} / 6$ \\
$\mathbf{u}_{7}(1,1,1)$ & $\mathrm{U}_{\mathrm{DC}} / 2$ & $\mathrm{U}_{\mathrm{DC}} / 2$ & $\mathrm{U}_{\mathrm{DC}} / 2$ & $\mathrm{U}_{\mathrm{DC}} / 2$ \\
\hline
\end{tabular}

Table. IV: Optimal switching table of DPC-EMC 1

\begin{tabular}{|l|l|l|}
\hline \multirow{2}{*}{$\mathrm{P} \Uparrow$} & $\mathrm{Q} \Uparrow$ & $\mathbf{u}_{\mathbf{k}+2}$ \\
\cline { 2 - 3 } & $\mathrm{Q} \Downarrow$ & $\mathbf{u}_{\mathbf{k}-2}$ \\
\hline $\mathrm{P} \Downarrow$ & $\mathrm{Q} \Uparrow$ & $\mathbf{u}_{\mathbf{k}}$ \\
\cline { 2 - 3 } & $\mathrm{Q} \Downarrow$ & $\mathbf{u}_{\mathbf{k}}$ \\
\hline
\end{tabular}

On the basis of the above, the control strategy summarized in Tab. IV can be inferred, which has been called DPCEMC 1.

This means that when the grid voltage vector lies in the odd (even) sector, only odd (even) voltage vectors are employed. In the end it is clear that, as long as the grid voltage vector lies in one sector, no common-mode voltage variation occurs.

Each commutation of the common-mode voltage appears only when the grid voltage vector goes from one sector to the adjacent one. Moreover, at each sector crossing, the common-mode voltage variation is the minimum achievable, equal in magnitude to $\mathrm{U}_{\mathrm{DC}} / 6$. Therefore in steady-state only six variations of the common-mode voltage of amplitude $\mathrm{U}_{\mathrm{DC}} / 6$ appear theoretically in each period of the grid frequency. However, the beneficial of a significant reduction of the common-mode emissions of the inverter is paid back with higher ripples both in the active and reactive power waveforms and finally with higher harmonic contents of the injected currents. It should be also remarked that the use of this DPC strategy is quite straightforward to apply, since the proper voltage space vector is created at every sampling time. This means that this strategy can be implemented just by using software commands.

\section{DPC-EMC 2}

DPC-EMC 2 has been devised to improve the drawbacks of DPC-EMC 1, i.e. high ripples of $\mathrm{P}$ and $\mathrm{Q}$ waveforms, high harmonic content of the injected currents (which is particularly important for distributed generation from renewable sources) and the presence of a bias in the controlled reactive power in generating mode. As a matter of fact, the poor control of the reactive power in generating mode is due to the fact that both the $\mathbf{u}_{\mathbf{k}+2}$ and $\mathbf{u}_{\mathbf{k}-2}$ voltage vectors cause small variations of the reactive power. On the contrary, $\mathbf{u}_{\mathbf{k}+\mathbf{1}}$ and $\mathbf{u}_{\mathbf{k}-\mathbf{1}}$ voltage vectors cause high variations of the reactive power (see Tab. I). DTC-EMC 2 is therefore based on the idea to employ DTC-EMC 1 strategy as far as reactive power error is sufficiently bounded and to use $\mathbf{u}_{\mathbf{k} \pm \mathbf{1}}$ voltage vectors only when high reactive power variations are required. This is achieved by using a 4-level hysteresis controller (Fig. 3) for Q control, instead of a 2-level one. In this way, when the $\mathrm{Q}$ error is low, the output of the controller is \pm 1 and thus vectors $\mathbf{u}_{\mathbf{k} \pm 2}$ are used (the controller coincide with that of the DPC-EMC 1). On the contrary, when the $\mathrm{Q}$ error is high the output of the controller is \pm 2 and thus vectors $\mathbf{u}_{\mathbf{k} \pm \mathbf{1}}$ are used. The control strategy is summarized in Tab. V.

Table. V: Optimal switching table of DPC-EMC 2

\begin{tabular}{|l|l|l|}
\hline \multirow{3}{*}{$\mathrm{P} \Downarrow$} & $\mathrm{Q} \Uparrow$ & $\mathbf{u}_{\mathbf{k}}$ \\
\cline { 2 - 3 } & $\mathrm{Q} \Downarrow$ & $\mathbf{u}_{\mathbf{k}}$ \\
\hline \multirow{3}{*}{$\mathrm{P} \Uparrow$} & $\mathrm{Q} \Uparrow \Uparrow$ & $\mathbf{u}_{\mathbf{k}+1}$ \\
\cline { 2 - 3 } & $\mathrm{Q} \Downarrow \Downarrow$ & $\mathbf{u}_{\mathbf{k}-1}$ \\
\hline \multirow{2}{*}{$\mathrm{P} \Uparrow$} & $\mathrm{Q} \Uparrow$ & $\mathbf{u}_{\mathbf{k}+2}$ \\
\cline { 2 - 3 } & $\mathrm{Q} \Downarrow$ & $\mathbf{u}_{\mathbf{k}-2}$ \\
\hline
\end{tabular}

The result is a better capability to control the Q error to zero (no reactive power exchanged with the grid), lower ripple in the $\mathrm{P}$ and $\mathrm{Q}$ waveforms and lower harmonic content of the injected currents. With regard to the common-mode voltage, the result is a waveform which is the six-step one of DPC-EMC 1 with few additional spikes due to the rare application of vectors $\mathbf{u}_{\mathbf{k} \pm \mathbf{1}}$ However, the harmonic content of the common-mode voltage at frequencies about some $\mathrm{kHz}$ slightly increases with respect to that of DPC-EMC 1 but this deterioration is negligible, and in any case much lower than that of Classic DPC.

\section{E. Virtual Flux}

To use the control techniques of the electric motors, broadly studied in literature, also in the sectors of the distributed generation and the active rectifiers the concept of "virtual motor" has been devised. It is possible to consider the electric grid as an equivalent virtual motor characterized by a transient leakage inductance (motor) 
equivalent to the connecting filter inductance of the inverter (active rectifier) and the back-electromotive force (motor) equivalent to the grid voltages (active rectifier). On the basis of this abstraction, the concept of virtual flux, equivalent to the magnetic flux of an electric motor, can be defined as the time integral of the grid voltages. The virtual flux is phase shifted of $90^{\circ}$ with respect to the grid voltage. The direct and quadrature components of the virtual flux in the stationary reference frame are:

$\psi_{g D}=\int\left(u_{s D}+L \frac{d i_{s D}}{d t}\right) d t$

$\psi_{g Q}=\int\left(u_{s Q}+L \frac{d i_{s Q}}{d t}\right) d t$

The use of the virtual flux in the VOC technique is based on the orientation of the rotating reference frame on the vector of the virtual flux rather than on the vector of the grid voltage. On the contrary, the use of the virtual flux in the DPC technique allows to calculate the active and reactive powers using the virtual flux rather than the grid voltage, that is more noisy. The estimation of the power based on the virtual flux is based on the following equations:

$$
\begin{aligned}
& P=\frac{3}{2} \omega\left(\psi_{g D} i_{s Q}-\psi_{d Q} i_{s D}\right) \\
& Q=\frac{3}{2} \omega\left(\psi_{g D} i_{s D}+\psi_{g Q} i_{s Q}\right)
\end{aligned}
$$

The advantages introduced with the virtual flux are a reduction of the harmonics in the grid current and in the ripples of the active and reactive powers. The estimation of the virtual flux for experimental applications requires an open loop integration. A simple way to solve this problem is to approximate the pure integrator with a $1^{\text {st }}$ order low pass filter.

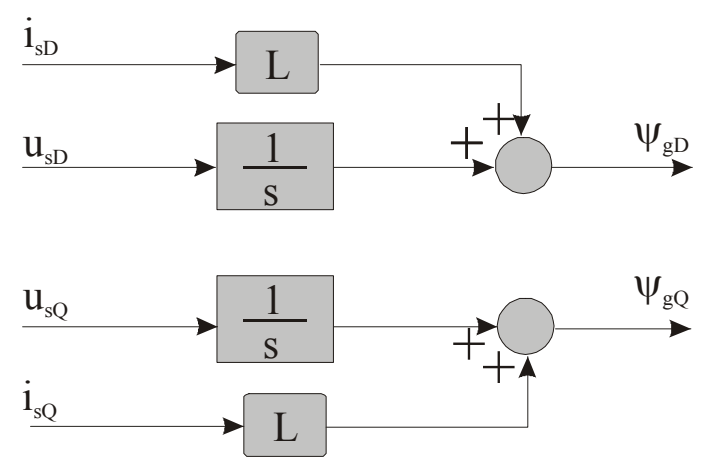

Fig. 4: Block diagram of the virtual-flux estimator

\section{Results}

All the 4 described control techniques - VOC, DPC, DPCEMC1 and DPC-EMC2 - with their virtual flux corresponding versions have been implemented in MatlabSimulink $^{\circledR}$ environment. In particular, for the circuital scheme analysis the PLECS ${ }^{\circledR}$ has been adopted. The PLECS software has been used for the IGBT 3-phase inverter, the interconnecting inductance and the voltage and current sensors. All the control algorithm has been implemented in classic Simulink, in the discrete domain. A sampling frequency of $15 \mathrm{kHz}$ has been adopted for the DPC, DPC-EMC1 and DPC-EMC2 (and corresponding virtual flux versions), while for the VOC and VF-OC a sampling frequency of $10 \mathrm{kHz}$ with a PWM frequency of 5 $\mathrm{kHz}$ has been adopted. Fig. $5 \mathrm{a}$ ) and b) show the steadystate inverter current time waveforms and their corresponding spectra obtained with the FFT (Fast Fourier Transform) up to the $40^{\text {th }}$ harmonics, obtained respectively with the VOC and VF-OC when a $P_{\text {ref }}=-2 \mathrm{~kW}, Q_{\text {ref }}=0$ VAR have been given as references. As expected, VF-OC exhibits a slightly better harmonic content of the injected current, both considering an harmonic-by-harmonic analysis and considering the \% THD equal respectively to $0.77 \%$ for the VOC and $0.72 \%$ for the VF-OC. Fig. 6 a) and b) show the steady-state inverter current time waveforms and their corresponding spectra under the same working conditions, respectively with the DPC and the VFDPC. As expected, VF-DPC exhibits a slightly better harmonic content of the injected current, both considering an harmonic-by-harmonic analysis and considering the $\%$ THD equal respectively to $11.47 \%$ for the DPC and $10.68 \%$ for the VF-DPC. Fig. 7 a) and b) show the steadystate inverter current time waveforms and their corresponding spectra under the same working conditions, respectively with the DPC-EMC1 and the VF-DPC-EMC1. Also in this case, VF-DPC-EMC1 exhibits a slightly better harmonic content of the injected current, both considering an harmonic-by-harmonic analysis and considering the \%THD equal respectively to $8.93 \%$ for the DPC-EMC1 and $8.36 \%$ for the VF-DPC-EMC1. Finally, Fig. 8 a) and b) show the steady-state inverter current time waveforms and their corresponding spectra under the same working conditions, respectively with the DPC-EMC2 and the VFDPC-EMC2. Also in this case, VF-DPC-EMC2 exhibits a slightly better harmonic content of the injected current, both considering an harmonic-by-harmonic analysis and considering the \%THD equal respectively to $7.77 \%$ for the DPC-EMC2 and $6.70 \%$ for the VF-DPC-EMC2. As a global comparative analysis, the \%THD of the injected current versus the generated power has been drawn for all control techniques. Fig. 9 shows the common-mode voltage generated by the inverter, respectively with DPC-EMC1 and DPC-EMC2, and their corresponding spectra obtained with the FFT. The common-mode voltage waveform is a square wave with fundamental frequency at $150 \mathrm{~Hz}$ and harmonics only at low frequency decreasing with inverse proportionality at increasing frequency. DPC-EMC 2 presents a common-mode voltage waveform which is a square wave at $150 \mathrm{~Hz}$ with some internal spikes; as a result its spectrum presents lower values of the low frequency harmonics and slightly higher values of the harmonics around higher frequencies than DPC-EMC 1. the Fig. 10, which draws this comparison, shows that in general VOC and VF-OC present better performances, especially for low values of the generated power. Among the different DPC techniques, the worst is the DPC while the best is the DPC-EMC2. Each of them presents an improvement in its virtual flux version. In general, whatever technique is used, the lower the generated power the higher harmonic content. It should be noted that only VOC and VF-OC satisfies the requirements of the European [13] and American [14] Standards, equal in both cases to $5 \%$. Fig. 11 shows \%THD 
of the injected current versus DC link voltage. The knowledge of the power quality issues related to the DC link value is particularly important, especially when this value cannot be considered constant. This figure shows that only VOC and VF-OC always respect the Standards limit. Other techniques are not complying with it for all values of voltage. With regard to DPC-EMC1 and DPC-EMC2 the trend is a significant increase of the THD for decreasing values of $\mathrm{V}_{\mathrm{dc}}$. Same considerations are true for $\mathrm{VOC}$, which however present a slight increase of the THD at lower values of $\mathrm{V}_{\mathrm{dc}}$. Finally, DPC does not present significant variations of the THD for the different values of $\mathrm{V}_{\mathrm{dc}}$.
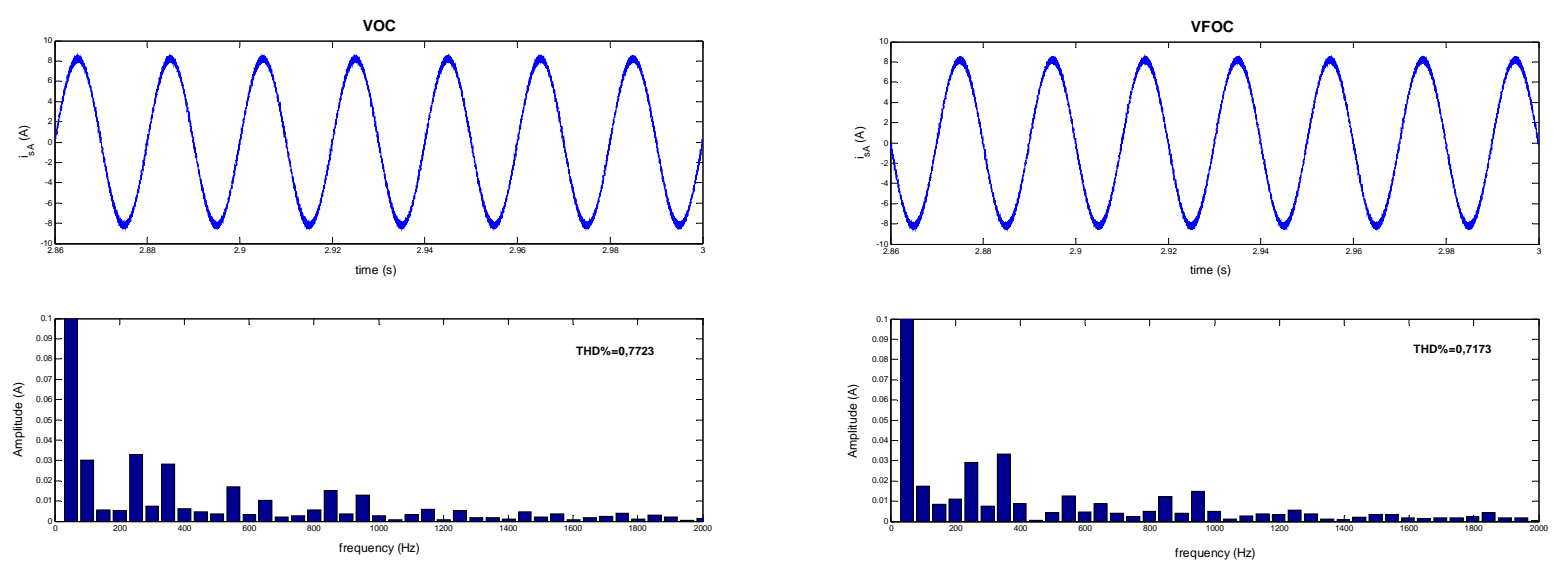

Fig. 5: Inverter current and its FFT at $P_{\text {ref }}=-2 \mathrm{~kW}, \mathrm{Q}_{\mathrm{ref}}=0 \mathrm{VAR}$ with VOC a) V-FOC b)
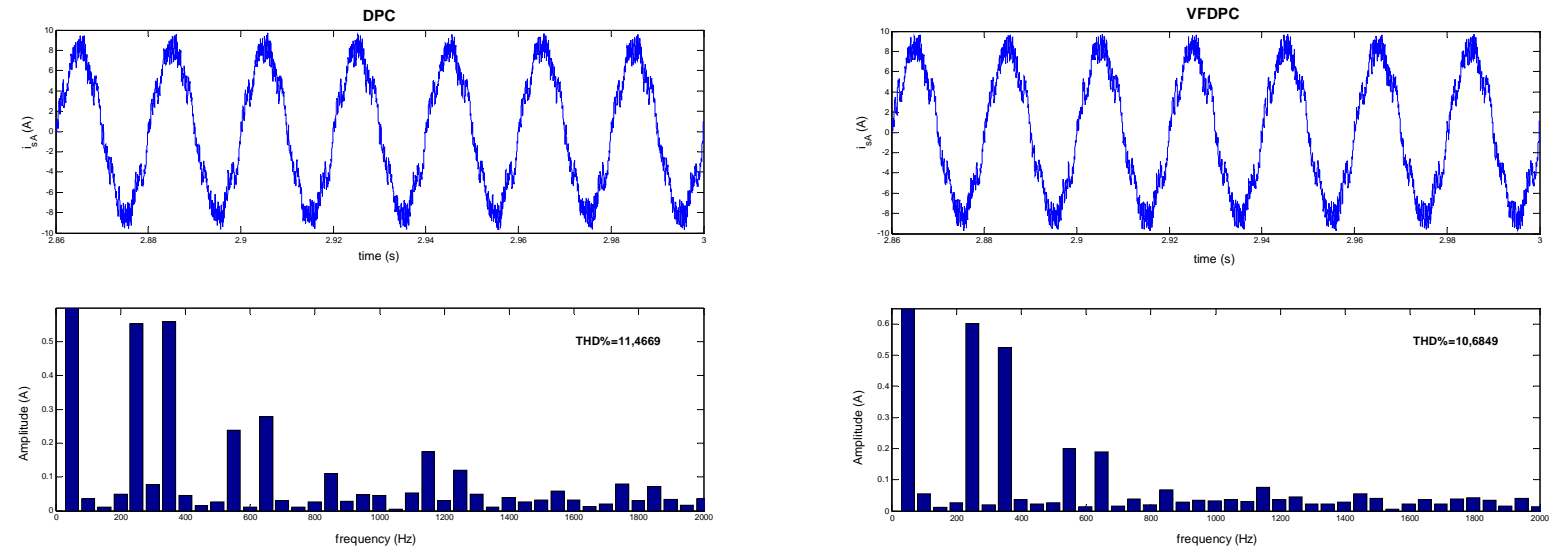

Fig. 6: Inverter current and its FFT at $\mathrm{P}_{\text {ref }}=-2 \mathrm{~kW}, \mathrm{Q}_{\mathrm{ref}}=0$ VAR with DPC a) VF-DPC b)

DPC-EMC
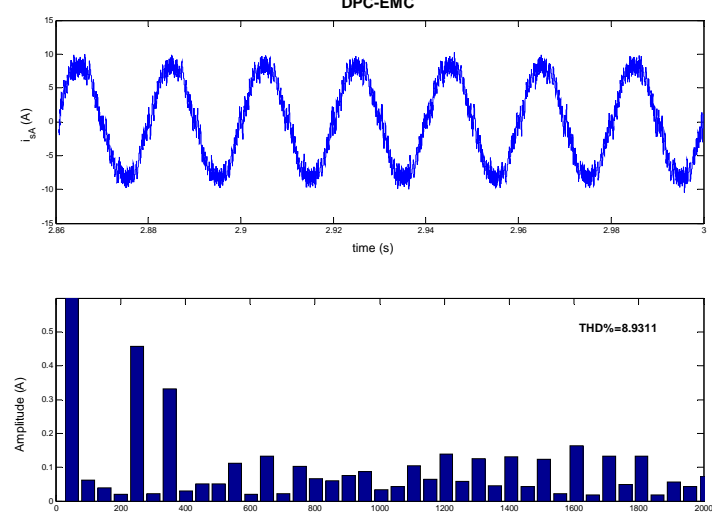

VFDPC-EMC
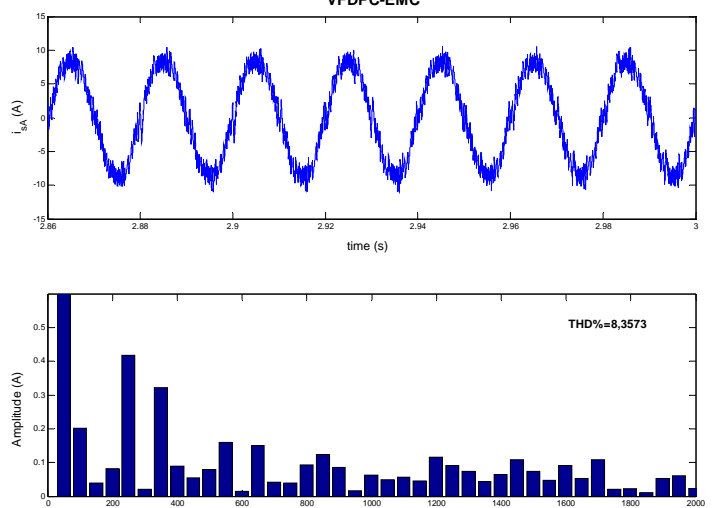

Fig. 7: Inverter current and FFT at $P_{\text {ref }}=-2 \mathrm{~kW}, \mathrm{Q}_{\text {ref }}=0$ VAR with DPC-EMC1 a) VF-DPC-EMC1 b) 

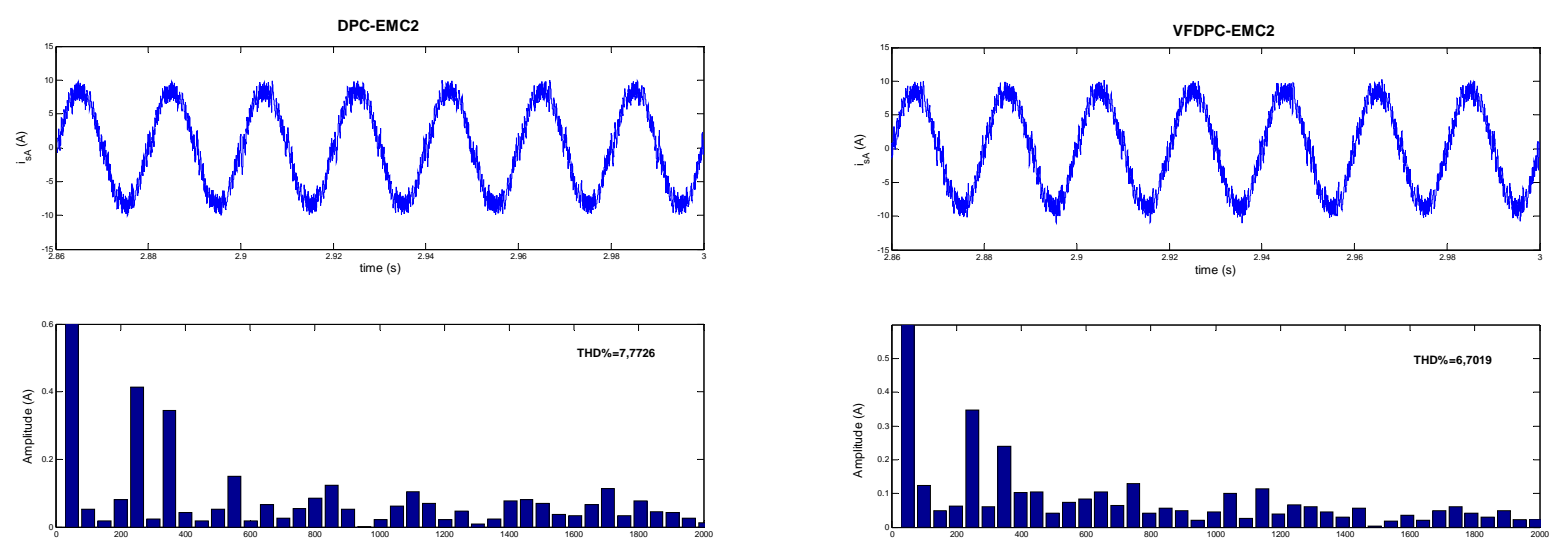

Fig. 8: Inverter current and FFT at $\mathrm{P}_{\text {ref }}=-2 \mathrm{~kW}, \mathrm{Q}_{\mathrm{ref}}=0$ VAR with DPC-EMC2 a) VF-DPC-EMC2 b)
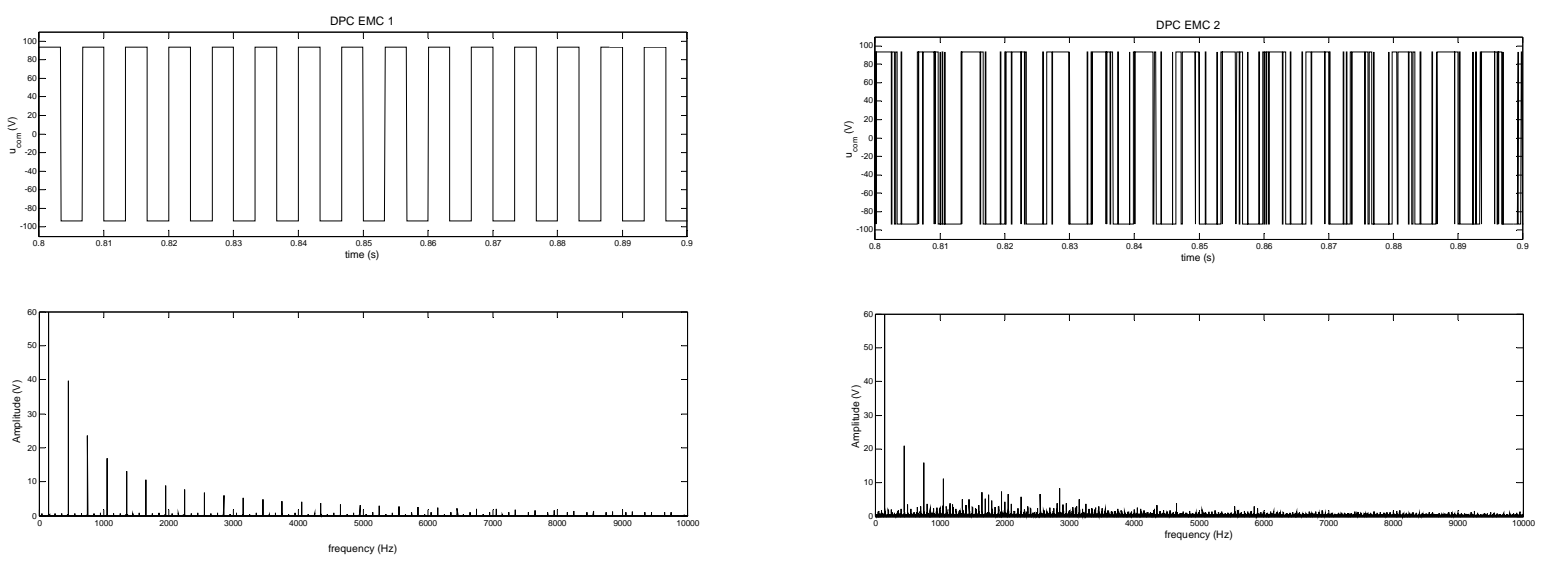

Fig. 9: Common-mode voltage and its FFT with DPC-EMC 1 a) and DPC-EMC 2 b)

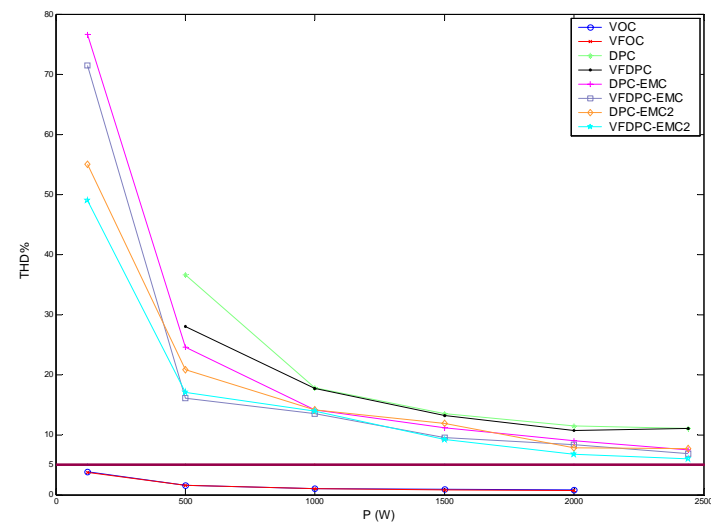

Fig. 10: \%THD of the injected current vs generated power (left)

\section{Conclusions}

This paper presents a comparison of VOC and DPC techniques, the related versions to minimize the common-mode emissions and their virtual flux based counterparts, focusing the attention to their behaviours when used in generating mode, e.g. for grid connected distributed generation systems from renewable sources.

Results have been compared from the point of view of the harmonic content of the currents injected into the grid

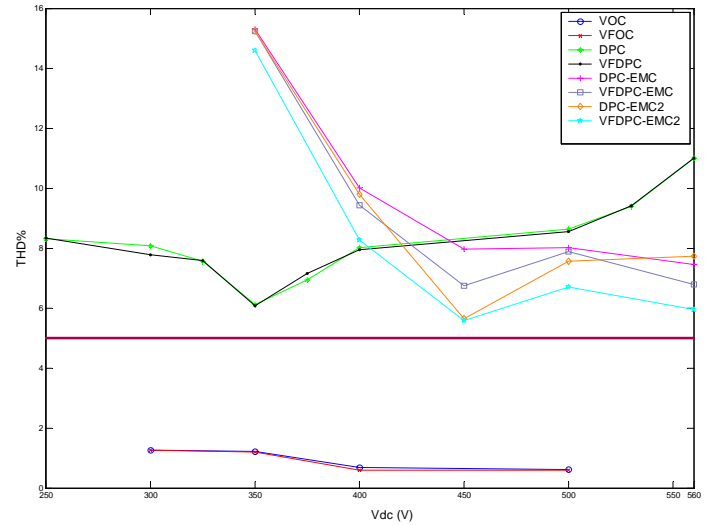

Fig. 11: \%THD of the injected current vs DC link voltage (right)

and their THDs at different levels of generated power. Results have been compared also with the requirements of the European and American Standards. The ratio between the DC link voltage and the grid voltage amplitude has been taken into account with regard to its influence on the THD of the injected currents. Results show that the best behaviour is presented by the VF-OC and VOC, followed by DPC-EMC1 and DPC-EMC2 (with the virtual flux versions) in many working conditions. Furthermore, these last techniques presents 
also the advantage to minimize significantly the common-mode emissions of the inverter towards the grid.

\section{Acknowledgements}

This work has been funded by the Italian MIUR project n. 211.

\section{List of Symbols}

$\mathbf{u}_{\mathrm{s}}{ }^{\mathrm{u}}=\mathrm{u}_{\mathrm{sd}}+\mathrm{j} \mathrm{u}_{\mathrm{sq}}$ : space vector of the inverter voltages in the grid voltage reference frame;

$\mathbf{u}_{\mathrm{g}}{ }^{\mathrm{u}}=\mathrm{u}_{\mathrm{gd}}+\mathrm{j} \mathrm{u}_{\mathrm{gq}}$ :space vector of the grid voltages in the grid voltage reference frame;

$\mathbf{i}_{\mathrm{s}}{ }^{\mathrm{u}}=\mathrm{i}_{\mathrm{d}}+\mathrm{j} \mathrm{i}_{\mathrm{q}}$ :space vector of the inverter currents in the grid voltage reference frame;

$\mathbf{u}_{\mathrm{sA}}, \mathbf{u}_{\mathrm{sB}}, \mathbf{u}_{\mathrm{sC}}$ : inverter phase voltages;

$\mathbf{u}_{\mathrm{k}}: \mathrm{k}$-th Inverter voltage vector

$\mathbf{i}_{\mathrm{SA}}, \mathbf{i}_{\mathrm{sB}}, \mathbf{i}_{\mathrm{sC}}$ : inverter phase currents;

$L, R$ : interconnection series inductance and its parasitic resistance;

$P, Q$ : active and reactive powers exchanged between the inverter and the grid;

$\omega=$ pulsation of the electrical grid;

\section{References}

[1] M.P. Kazmierkowski, R. Krishnan and F. Blaabjerg, Control in Power Electronics, London, UK, 2002.

[2] M. P. Kazmierkowski, "Current Control Techniques for Three-Phase Voltage-Source PWM Converters : A Survey", IEEE Transactions on Industrial Electronics, vol. 45, n. 5, October 1998, pp. 691703.

[3] M.P. Kazmierkowski, and H. Tunia, Automatic Control of Converter-Fed Drives, The Netherlands: Elsevier, 1994.

[4] S. Hansen, M. Malinowski, F. Blaabjerg, M.P. Kazmierkowski, "Sensorless control strategies for PWM rectifier", APEC 2000 (Applied Power Electronics Conference and Exposition), vol. 2, 610 Feb. 2000, pp. $832-838$.

[5] M. Liserre, A. Dell'Aquila, F. Blaabjerg, "An Overview of the Three-Phase Voltage Source Active Rectifiers Interfacing the Utility", Powertech Conference 2003, June 23-26, Bologna, Italy.

[6] T. Noguchi, H. Tomini, S. Kondo, "Direct Power Control of PWM Converter Without Power-Source Voltage Sensor", IEEE Transactions on Industry Applications, Vol. 34, n. 3, May-June 1998, pp. 473479.

[7] M. Malinowski, Sensorless Control Strategies for Three - Phase PWM Rectifiers, PhD Thesis, University of Warsaw, Poland - 2001.

[8] M. Malinowski, M.P. Kazmierkowski, S. Hansen, F. Blaabjerg, "Virtual-Flux-Based Direct Power Control of Three-Phase PWM Rectifiers", IEEE Transactions on Industry Applications, Vol. 37, n. 4, July-August 2001, pp. 1019-1027.
[9] M. Malinowski, M.P. Kazmierkowski, M. Trzynadlowski, "A Comparative Study of Control Techniques for PWM Rectifiers in AC Adjustable Speed Drives", IEEE Transactions on Power Electronics, vol. 18, n. 6, November 2003, pp. 13901396.

[10] G. Giglia, C. Serporta, M. Pucci, G. Vitale, "Experimental Comparison of Three-Phase Distributed Generation Systems Based on VOC and DPC Control Techniques", EPE 2007 European Conference on Power Electronics and Applications, 2-5 september 2007, Aalborg, Denmark.

[11] M. Cirrincione, M. Pucci, G. Vitale, "Direct Power Control of Three-Phase VSIs for the Minimization of Common-Mode Emissions in Distributed Generation Systems", ISIE 2007 IEEE International Symposium on Industrial Electronics ISIE07, 4-7 June 2007 Vigo (Spain).

[12] M. Cirrincione, M. Pucci, G. Vitale, "New Direct Power Control Strategies of Three-Phase VSIs for the Minimization of Common-Mode Emissions in Distributed Generation Systems", The Forty-second Annual Meeting of the IEEE Industry Applications Society (IAS 2007) New-Orleans USA Sept. 23 - 27, 2007.

[13] Standard IEC/EN61727, Photovoltaic (PV) Systems - Characteristics of the utility interface, IEC Std, 1997

[14] IEEE 1547-2003, Standard for Interconnecting Distributed Resources with Electric Power Systems, 2003. 